\title{
Rapid Progression of Vascular and Soft Tissue Calcification while Being Managed for Severe and Persistent Hypocalcemia Induced by Denosumab Treatment in a Patient with Multiple Myeloma and Chronic Kidney Disease
}

\author{
Kenji Ueki ${ }^{1}$, Shunsuke Yamada ${ }^{1,2}$, Akihiro Tsuchimoto ${ }^{1}$, Masanori Tokumoto ${ }^{2}$, \\ Takashi Kumano $^{3}$, Takanari Kitazono ${ }^{1}$ and Kazuhiko Tsuruya ${ }^{1,4}$
}

\begin{abstract}
We herein present the case of a patient with myeloma and chronic kidney disease (CKD) who developed rapidly progressive vascular and soft tissue calcification during the course of treatment for severe hypocalcemia induced by the administration of denosumab for myeloma and hypercalcemia. Because a large amount of supplementation with active vitamin D and calcium was required to correct the severe hypocalcemia, rapidly progressive vascular calcification developed. Seeing that patients with CKD are prone to developing severe and prolonged hypocalcemia after denosumab treatment, physicians should closely monitor the patients' serum calcium levels and manage their hypocalcemia appropriately so as to avoid the development of significant ectopic calcification.
\end{abstract}

Key words: chronic kidney disease, denosumab, hypocalcemia, myeloma, vascular calcification

(Intern Med 54: 2637-2642, 2015)

(DOI: 10.2169/internalmedicine.54.4946)

\section{Introduction}

Denosumab is a fully humanized anti-monoclonal antibody to the receptor activator of nuclear- $\kappa \beta$ ligand (RANKL) (1) used in patients with osteoporosis and/or skeletal disorders secondary to malignancy, including multiple myeloma and solid tumors (breast and prostate cancer) (1-3). Hypercalcemia, often complicated by myeloma and metastatic cancer, is another therapeutic target of denosumab (4). Myeloma cells in the bone promote the proliferation and maturation of osteoclasts by stimulating the receptor activator of nuclear- $\kappa \beta$ and RANKL axis, leading to increased bone resorption and resultant hypercalcemia (5). Accordingly, when denosumab is administered in these patients, myeloma-related hypercalcemia is markedly suppressed.

One critical adverse event related to denosumab therapy is hypocalcemia (6). Whereas the prevalence of hypocalcemia ranges from only 0.05 to $5.5 \%$ in postmenopausal females and the degree of hypocalcemia is generally mild and transient, clinical studies suggest that patients with chronic kidney disease (CKD) tend to develop severe and protracted hypocalcemia, with an incidence of hypocalcemia reaching $30 \%$ of CKD patients (6-10).

We herein report the case of a patient with multiple myeloma and CKD who rapidly developed severe and persistent hypocalcemia after receiving denosumab for multiple myeloma with hypercalcemia and skeletal complications. Unfortunately, treatment to correct the hypocalcemia with calcium (Ca) and phosphate (Pi)-containing agents and vitamin D receptor (VDR) activator quickly induced the onset of soft tissue and vascular calcification.

\footnotetext{
${ }^{1}$ Department of Medicine and Clinical Science, Graduate School of Medical Sciences, Kyushu University, Japan, ${ }^{2}$ Department of Internal Medicine, Fukuoka Dental College, Japan, ${ }^{3}$ Division of Hematology and Oncology, Fukuoka Sanno Hospital, Japan and ${ }^{4}$ Department of Integrated Therapy for Chronic Kidney Disease, Graduate School of Medical Sciences, Kyushu University, Japan

Received for publication January 12, 2015; Accepted for publication February 23, 2015

Correspondence to Dr. Kazuhiko Tsuruya, tsuruya@intmed2.med.kyushu-u.ac.jp
} 
Table. Laboratory Data at the Time of First Admission.

\begin{tabular}{|c|c|c|c|c|c|}
\hline Complete blood count & & & Lactate dehydrogenase & 455 & $\mathrm{U} / \mathrm{L}$ \\
\hline Hemoglobin & 5.6 & $\mathrm{~g} / \mathrm{dL}$ & Glucose & 122 & $\mathrm{mg} / \mathrm{dL}$ \\
\hline Hematocrit & 16.9 & $\%$ & Total cholesterol & 204 & $\mathrm{mg} / \mathrm{dL}$ \\
\hline White blood cells & 8,140 & $/ \mu \mathrm{L}$ & Triglyceride & 151 & $\mathrm{mg} / \mathrm{dL}$ \\
\hline Neutrophils & 51.4 & $\%$ & HDL-cholesterol & 75 & $\mathrm{mg} / \mathrm{dL}$ \\
\hline \multirow[t]{2}{*}{ Platelets $\left(\times 10^{4}\right)$} & 11.4 & $/ \mu \mathrm{L}$ & LDL-cholesterol & 99 & $\mathrm{mg} / \mathrm{dL}$ \\
\hline & & & C-reactive protein & 0.12 & $\mathrm{mg} / \mathrm{dL}$ \\
\hline \multicolumn{6}{|l|}{ Serum biochemistry } \\
\hline Total protein & 7.4 & $\mathrm{~g} / \mathrm{dL}$ & Immunological studies & & \\
\hline Albumin & 3.5 & $\mathrm{~g} / \mathrm{dL}$ & Immunoglobulin G & 355 & $\mathrm{mg} / \mathrm{dL}$ \\
\hline Blood urea nitrogen & 55 & $\mathrm{mg} / \mathrm{dL}$ & Immunoglobulin A & 1,069 & $\mathrm{mg} / \mathrm{dL}$ \\
\hline Creatinine & 4.92 & $\mathrm{mg} / \mathrm{dL}$ & Immunoglobulin $\mathrm{M}$ & 8 & $\mathrm{mg} / \mathrm{dL}$ \\
\hline Uric acid & 9.6 & $\mathrm{mg} / \mathrm{dL}$ & Immunoglobulin D & $<0.6$ & $\mathrm{mg} / \mathrm{dL}$ \\
\hline Calcium & 13.4 & $\mathrm{mg} / \mathrm{dL}$ & FLC $\kappa$ type light chain & 7.8 & $\mathrm{mg} / \mathrm{dL}$ \\
\hline Albumin-corrected calcium & 13.9 & $\mathrm{mg} / \mathrm{dL}$ & FLC $\lambda$ type light chain & 12,800 & $\mathrm{mg} / \mathrm{dL}$ \\
\hline Phosphate & 4.9 & $\mathrm{mg} / \mathrm{dL}$ & $\beta_{2}$-microglobulin & 41.7 & $\mathrm{mg} / \mathrm{L}$ \\
\hline Sodium & 138 & $\mathrm{mmol} / \mathrm{L}$ & & & \\
\hline Potassium & 4.4 & $\mathrm{mmol} / \mathrm{L}$ & Urinalysis & & \\
\hline Chloride & 100 & $\mathrm{mmol} / \mathrm{L}$ & $\mathrm{pH}$ & 6.0 & \\
\hline Total bilirubin & 0.4 & $\mathrm{mg} / \mathrm{dL}$ & Blood & $1+$ & \\
\hline Aspartate aminotransferase & 23 & $\mathrm{U} / \mathrm{L}$ & Protein & $2+$ & \\
\hline Alanine aminotransferase & 19 & $\mathrm{U} / \mathrm{L}$ & Sugar & $(-)$ & \\
\hline Alkaline phosphatase & 623 & $\mathrm{U} / \mathrm{L}$ & White blood cells & $(-)$ & \\
\hline$\gamma$-glutamyl transpeptidase & 67 & $\mathrm{U} / \mathrm{L}$ & Protein/creatinine ratio & 8.18 & \\
\hline
\end{tabular}

HDL: high-density lipoprotein, LDL: low-density lipoprotein.

\section{Case Report}

A 57-year-old woman was admitted to the department of hematology at our hospital for the management of general fatigue, anemia, and kidney dysfunction. One year prior to admission, she had a serum creatinine $(\mathrm{Cr})$ level of $0.57 \mathrm{mg} /$ $\mathrm{dL}$ and her urinalysis showed no abnormalities.

On her first admission, the patient was alert. Blood tests showed a hemoglobin level of $5.6 \mathrm{~g} / \mathrm{dL}$, white blood cell count of $8,140 / \mu \mathrm{L}$, platelet count of $11.4 \times 10^{4} / \mu \mathrm{L}$, serum albumin level of $3.5 \mathrm{~g} / \mathrm{dL}$, blood urea nitrogen level of $55 \mathrm{mg} /$ $\mathrm{dL}$, serum Cr level of $4.9 \mathrm{mg} / \mathrm{dL}$, Ca level of $13.4 \mathrm{mg} / \mathrm{dL}$, Pi level of $4.9 \mathrm{mg} / \mathrm{dL}$, alkaline phosphatase (ALP) level of $623 \mathrm{U} / \mathrm{L}$, and C-reactive protein level of $0.12 \mathrm{mg} / \mathrm{dL}$. Her urinary protein $\mathrm{Cr}$ ratio was $8.1 \mathrm{~g} / \mathrm{gCr}$. A summary of these data is shown in Table. Radiography showed multiple punched out lesions in the cranium, and the results of a bone marrow biopsy, flow cytometry and other diagnostic modalities ultimately led to a diagnosis of multiple myeloma (IgA + Bence-Jones $\lambda$ type, Stage IIIB). Bone metastases in the cranium, ribs, and vertebrae were suspected on computed tomography and bone scintigraphy. At that time, no ectopic calcification was detected on the computed tomography scans (Fig. 1). Although a kidney biopsy was not performed, myeloma kidney and/or amyloidosis were the most likely causes of the kidney dysfunction and significant proteinuria. Saline was administered to the patient intravenously to correct her dehydration and treat her hypercalcemia, which subsequently aggravated the hydrothorax. At that point, we decided to use denosumab for three reasons. First, we could not control the hypercalcemia with a preservative approach. Second, the skeletal lesions related to myeloma were closely associated with the hypercalcemia. Third, denosumab can be used to control the activity of myeloma and its related local bone resorption.

Denosumab (120 mg/body) was administered intravenously to treat the patient's bone metastases and hypercalcemia, which resulted in a rapid decline in the serum calcium level (Fig. 2). Because the corrected serum Ca level reached $6.5 \mathrm{mg} / \mathrm{dL}$ at its lowest point, the patient was treated with oral $\mathrm{Ca}$ supplementation (Ca phosphate: 3.5-4.0 g/day) and VDR activator (0.5-3.0 $\mu \mathrm{g} /$ day). She also required intravenous $\mathrm{Ca}$ supplementation (Ca gluconate: $0.4-4.0 \mathrm{~g} /$ week) intermittently to maintain a corrected serum $\mathrm{Ca}$ level of approximately 8-9 mg/dL. After achieving control of the hypocalcemia, the patient was treated with bortezomib (1.3 $\mathrm{mg} / \mathrm{m}^{2}$ ) and dexamethasone (20 mg/body) for myeloma, followed by bortezomib $\left(1.3 \mathrm{mg} / \mathrm{m}^{2}\right)$, cyclophosphamide $(500$ $\mathrm{mg} /$ body), and dexamethasone (20 mg/body) thereafter. Because the serum Ca level was maintained within the low to normal range with the oral administration of Ca-containing agents (Ca lactate: 1.0-3.0 g/day) and VDR activator (alfacalcidol: $1 \mu \mathrm{g} /$ day), she was discharged. After discharge, she continued to receive chemotherapy (bortezomib: $1.3 \mathrm{mg} / \mathrm{m}^{2}$, cyclophosphamide: $500 \mathrm{mg} /$ body, and dexamethasone: 20 $\mathrm{mg} /$ body) in the outpatient department. However, the anorexia persisted and her serum Cr level gradually increased. Finally, she was again hospitalized and our nephrology department was consulted for management of her kidney dysfunction and sustained hypocalcemia.

At the time of consultation, the patient had a serum $\mathrm{Cr}$ level of $7.44 \mathrm{mg} / \mathrm{dL}$, corrected serum Ca level of $7.5 \mathrm{mg} / \mathrm{dL}$, serum Pi level of $11.9 \mathrm{mg} / \mathrm{dL}$, serum intact parathyroid hor- 


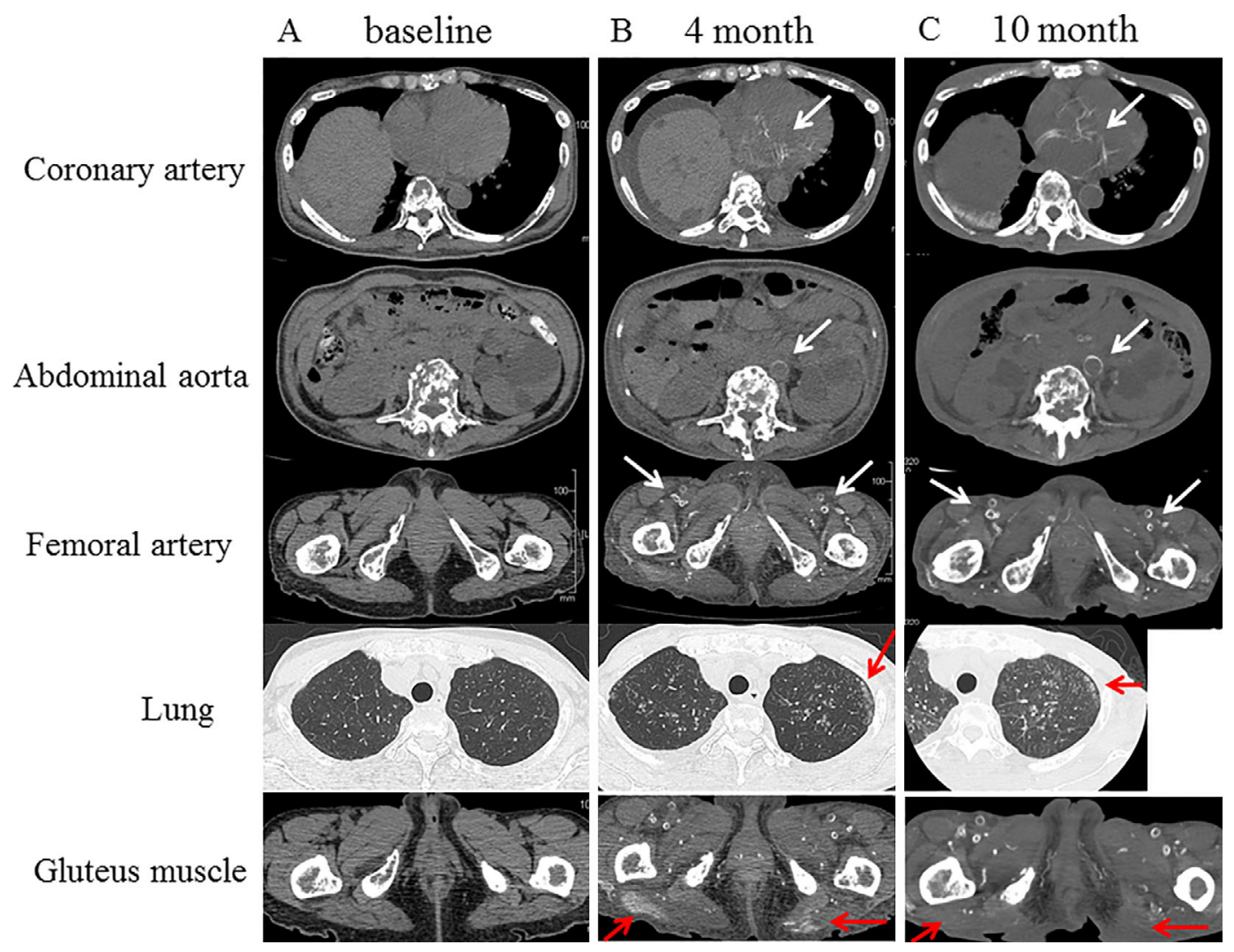

Figure 1. Time course of vascular and soft tissue calcification on computed tomography at each time period. Representative imaging of computer tomography at (A) baseline, (B) 4 months, and (C) 10 months from the first admission. Vascular calcification developed in the coronary artery, abdominal aorta, and femoral artery as early as at $\mathbf{4}$ months and progressed further at $\mathbf{1 0}$ months. Calcification in the lung and gluteal muscle developed as early as at $\mathbf{4}$ months. However, calcification in the gluteal muscle subsided at $\mathbf{1 0}$ months. The white and red arrows show vascular and soft tissue calcification.

mone (PTH) level of $149 \mathrm{pg} / \mathrm{mL}$, serum ALP level of 159 $\mathrm{U} / \mathrm{L}$, serum bone-specific ALP level of $8.3 \mathrm{U} / \mathrm{L}(\mathrm{N} ; 35 \mathrm{U} / \mathrm{L})$, and serum tartrate resistant acid phosphatase $5 \mathrm{~b}$ level of 326 $\mathrm{mU} / \mathrm{L}(\mathrm{N} ; 550 \mathrm{mU} / \mathrm{L})$. Her serum calcitriol level was not determined. Her urinary $\mathrm{Ca} / \mathrm{Cr}$ ratio was $0.07 \mathrm{mg} / \mathrm{gCr}$. Computed tomography revealed that the systemic soft tissue calcification (lungs and gluteal muscles) and vascular calcification (coronary artery, abdominal aorta and femoral artery) had progressed over the past four months (Fig. 1). Because Pi-based Ca supplementation was thought to be the primary cause of the rapidly progressive ectopic calcification, we replaced the Pi-containing $\mathrm{Ca}$ supplement with $\mathrm{Ca}$ acetate. In addition, as the acute exacerbation of the patient's kidney function was attributable to dehydration, saline was administered intravenously, which achieved a decline in the serum $\mathrm{Cr}$ level to the baseline value $(\mathrm{Cr} 4.5 \mathrm{mg} / \mathrm{dL})$. Meanwhile, the serum $\mathrm{Ca}$ and $\mathrm{Pi}$ levels were controlled with treatment consisting of $1 \mu \mathrm{g} /$ day of alfacalcidol and 1-3 g/day of $\mathrm{Ca}$ acetate.

Although the serum $\mathrm{Ca}$ and $\mathrm{Pi}$ levels were mostly well maintained within the target range under minimal doses of alfacalcidol ( $1 \mu \mathrm{g} /$ day) and Ca lactate (1-3 g/day), a computed tomography scan revealed that the vascular calcifica- tion and soft tissue calcification had further progressed at 10 months (Fig. 1). While the patient continued to receive chemotherapy (bortezomib: $1.3 \mathrm{mg} / \mathrm{m}^{2}$, thalidomide: $100 \mathrm{mg}$ / body and dexamethasone: $20 \mathrm{mg} /$ body) during the third hospitalization, the myeloma progressed and she was again treated with denosumab $(120 \mathrm{mg})$, followed by the onset of hypocalcemia. She finally died during her fourth admission due to progression of the myeloma.

\section{Discussion}

Clinical studies have identified the risk factors for hypocalcemia induced by denosumab use, they include: older age, pre-existing high bone turnover, malnutrition, low PTH level, the dose of denosumab administered, vitamin D deficiency, and CKD (6-10). Because denosumab strongly inhibits the maturation and activation of osteoclasts, the efflux of $\mathrm{Ca}$ from the bone stimulated by activated osteoclasts decreases, whereas the influx of $\mathrm{Ca}$ into the bone mediated by activated osteoblasts continues, resulting in a decrease in the serum $\mathrm{Ca}$ level; this phenomenon is also seen in patients treated with anti-bone resorption drugs, such as bisphosphonates. Because the target of bisphosphonate is also os- 


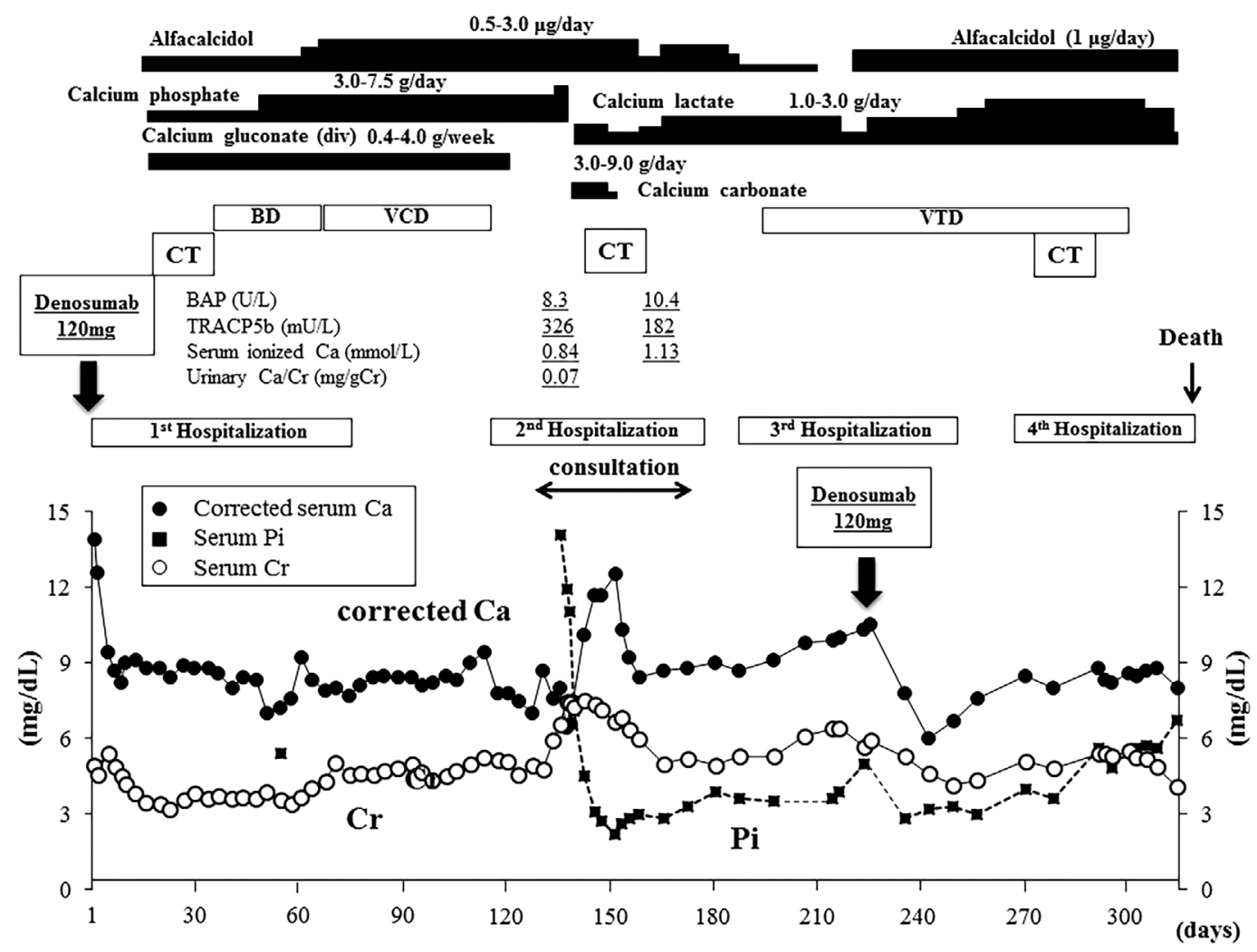

Figure 2. Clinical course. The clinical course of this patient is shown. BD: bortezomib and dexamethasone, Ca: calcium, Cr: creatinine, CT: computed tomography, Pi: phosphate, VCD: bortezomib, cyclophosphamide, and dexamethasone, VTD: bortezomib, thalidomide, and dexamethasone, BAP: bone type alkaline phosphatase, TRACP5b: tartrate resistant acid phosphatase 5b

teoclasts, bisphosphonate shares the risk factors for hypocalcemia with denosumab (11). In the present case, analyzing the high serum ALP level (613 U/L) and bone metastases confirmed on radiograms, the rate of bone turnover increased at the time of the first hospitalization, although bone formation is often suppressed in patients with advanced myeloma-related bone metastases (5). However, the serum ALP level decreased to the normal range (169 U/L) after denosumab treatment, and the bone specific ALP level remained within the normal range during the patient's second hospitalization. These results indicate that bone turnover was suppressed after treatment with denosumab and bortezomib, followed by a sustained decrease in $\mathrm{Ca}$ inflow from the bone, thus promoting the prolonged and severe hypocalcemia observed in the present case.

Generally, hypocalcemia strongly stimulates PTH secretion and is subsequently followed by an increased production of calcitriol in the kidneys and enhanced uptake of $\mathrm{Ca}$ from the gastrointestinal tract, which normalizes the serum Ca level (12). However, in CKD patients, the level of PTH is already increased as a result of secondary hyperparathyroidism. Furthermore, PTH resistance develops in the bone and the baseline serum calcitriol level is low; thus, the aforementioned rescue system does not function effectively and the hypocalcemia becomes severe and persistent, as in the present case. In this regard, hypocalcemia secondary to denosumab treatment tends to be severe and prolonged in
CKD patients (6-10).

Epidemiological studies have shown that there is a variety of risk factors for ectopic calcification, including high serum levels of $\mathrm{Ca}, \mathrm{Pi}$ and parathyroid hormone, the administration of VDR activator, alkalemia and the use of aluminum-based medicines $(12,13)$. In the present case, both the serum $\mathrm{Ca}$ and Pi levels were increased. As for vitamin D, a relatively high dose of VDR activator is administered in patients with advanced CKD, although the serum calcitriol levels have not been determined; the VDR activator promotes ectopic calcification by enhancing the absorption of $\mathrm{Ca}$ and $\mathrm{Pi}$ from the gastrointestinal tract. In the present case, the serum PTH level was decreased under hypercalcemia, and the rate of bone turnover was decreased after denosumab treatment. Because bone turnover is closely related to the buffer function of $\mathrm{Ca}$ and $\mathrm{Pi}$, low turnover accelerates ectopic calcification (14). In the current case, the blood $\mathrm{pH}$ level was slightly acidic or normal. Because aluminum-based drugs were not prescribed, aluminum-related osteopathy was not involved in the onset of ectopic calcification; aluminumassociated bone diseases are usually observed in dialysis patients receiving treatment with aluminum-based $\mathrm{Pi}$ binder (15). Collectively, the combination of these factors promoting ectopic calcification was involved in the present case, although not all known factors were present. However, it remains unclear as to why only limited patients develop severe hypocalcemia. Therefore, physicians should be vigi- 
lant of the possibility for hypocalcemia when administering denosumab in patients with CKD.

Vascular calcification is a serious complication of CKD (16). In the present case, the use of an excessive dose of VDR activator and $\mathrm{Pi}$ loading with the $\mathrm{Ca}$ supplement may have promoted the development of vascular and soft tissue calcification, as VDR activator directly promotes vascular calcification and $\mathrm{Pi}$ is a strong simultaneous inducer of various calcification pathways, including the osteogenic transdifferentiation of vascular smooth muscle cells. For this reason, minimal doses of non-Pi-containing $\mathrm{Ca}$ agents and VDR activators should have been administered in this case. Interestingly, the vascular calcification progressed even after the patient's serum Pi level was controlled, whereas the calcification in the gluteal muscles was ameliorated. These results indicate that soft tissue calcification may regress if the serum levels of $\mathrm{Ca}$ and $\mathrm{Pi}$ are appropriately controlled (17). In contrast, vascular calcification is a complex cell-mediated process orchestrated by various factors, including uremic toxins, and thus may be difficult to reverse or even halt the progression of vascular calcification.

In general, hypocalcemia should be treated with $\mathrm{Ca}$ and native vitamin $\mathrm{D}$. In subjects with $\mathrm{CKD}$, the active form of vitamin $\mathrm{D}$, not native vitamin $\mathrm{D}$, is preferable because the hydroxylation of 25-hydroxy vitamin $\mathrm{D}$ is impaired in these patients $(8,18)$. Importantly, the administration of high-dose $\mathrm{Ca}$ and vitamin $\mathrm{D}$ supplementation is often accompanied by increased urinary $\mathrm{Ca}$ excretion that subsequently aggravates CKD (19). Soft tissue and vascular calcification may be promoted in some cases, as a large amount of $\mathrm{Ca}$ and Pi precipitates in soft tissue instead of hard tissues, such as bone (20). In the present case, both the serum PTH and ALP levels were suppressed after treatment, indicating that decreased bone turnover accelerated the onset of ectopic calcification. Hence, the use of a minimum dose of supplementation is appropriate in CKD patients. In addition, dose reduction of denosumab should be considered because the half-life of this drug is very long. Moreover, the serum Ca level should be monitored with the serum ionized $\mathrm{Ca}$ level because the physiological function of $\mathrm{Ca}$ is closely related to the ionized $\mathrm{Ca}$ level and measurements of the total $\mathrm{Ca}$ level have not been proven to be accurate under the conditions of hypoalbuminemia. If we had used the ionized $\mathrm{Ca}$ level as a marker of the serum $\mathrm{Ca}$ level instead of the total Ca level corrected by serum albumin, we may have applied a lower dose of $\mathrm{Ca}$ and VDR activator to correct the hypocalcemia.

A previous experimental study showed the protective effects of denosumab against vascular calcification (21). In the present case, soft tissue and vascular calcification progressed. In contrast, a recent study showed that treatment with denosumab does not prevent arterial calcification in postmenopausal females with osteoporosis (22). Furthermore, some studies have revealed that osteoclast-like cells co-exist at calcified sites in blood vessels and interact with osteoblast-like cells in these vessels, although it remains un- known whether local osteoclasts have protective effects on vascular calcification, indicating a possible target (23). In the present case, vascular calcification progressed despite the use of denosumab. This observation may partly be due to the overload of both vitamin D derivatives and the Piincluding $\mathrm{Ca}$ supplement, which exceeded the protective effects of denosumab against vascular calcification. Therefore, further studies are needed to clarify the protective effects of denosumab in patients with vascular calcification.

In conclusion, because CKD patients are likely to develop severe and protracted hypocalcemia after receiving denosumab, physicians should carefully determine the indications for and the appropriate dosage of denosumab and closely monitor the serum $\mathrm{Ca}$ and $\mathrm{Pi}$ levels, correcting these serum parameters appropriately to prevent ectopic calcification.

\section{Author's disclosure of potential Conflicts of Interest (COI).}

Masanori Tokumoto: Honoraria, Kyowa Hakko Kirin, Chugai Pharmaceutical, Fuso Pharmaceutical Industries and Torii Pharmaceutical; Research funding, Kyowa Hakko Kirin. Kazuhiko Tsuruya: Honoraria, Kyowa Hakko Kirin and Chugai Pharmaceutical; Research funding, Kyowa Hakko Kirin, Chugai Pharmaceutical, Fuso Pharmaceutical Industries, MSD and Takeda Pharmaceutical; Endowed department, Baxter.

\section{References}

1. Moen MD, Keam SJ. Denosumab: a review of its use in the treatment of postmenopausal osteoporosis. Drugs Aging 28: 63-82, 2011.

2. McClung MR, Lewiecki EM, Cohen SB, et al. Denosumab in postmenopausal women with low bone mineral density. N Engl J Med 354: 821-831, 2006.

3. Fizazi K, Lipton A, Mariette X, et al. Randomized phase II trial of denosumab in patients with bone metastases from prostate cancer, breast cancer, or other neoplasms after intravenous bisphosphonates. J Clin Oncol 27: 1564-1571, 2009.

4. Roodman GD. Pathogenesis of myeloma bone disease. Leukemia 23: 435-441, 2009.

5. Hu MI, Glezerman IG, Leboulleux S, et al. Denosumab for treatment of hypercalcemia of malignancy. J Clin Endocrinol Metab 99: 3144-3152, 2014.

6. Block GA, Bone HG, Fang L, Lee E, Padhi D. A single-dose study of denosumab in patients with various degrees of renal impairment. J Bone Miner Res 27: 1471-1479, 2012.

7. Ungprasert P, Cheungpasitporn W, Srivali N, Kittanamongkolchai W, Bischof EF. Life-threatening hypocalcemia associated with denosumab in a patient with moderate renal insufficiency. Am J Emerg Med 31: 756.e1-756.e2, 2013.

8. Farinola N, Kanjanapan Y. Denosumab-induced hypocalcaemia in high bone turnover states of malignancy and secondary hyperparathyroidism from renal failure. Intern Med J 43: 1243-1246, 2013.

9. McCormick BB, Davis J, Burns KD. Severe hypocalcemia following denosumab injection in a hemodialysis patient. Am J Kidney Dis 60: 626-628, 2012.

10. Teng J, Abell S, Hicks RJ, et al. Protracted hypocalcaemia following a single dose of denosumab in humoral hypercalcaemia of malignancy due to PTHrP-secreting neuroendocrine tumour. Clin Endocrinol (Oxf) 81: 940-942, 2014.

11. Ho JW. Bisphosphonate stimulation of osteoblasts and osteoblastic metastasis as a mechanism of hypocalcaemia. Med Hypotheses 78: 
377-379, 2012.

12. Pecovnik-Balon B, Kramberger S. Tumoral calcinosis in patients on hemodialysis. Case report and review of the literature. Am J Nephrol 17: 93-95, 1997.

13. Fernández E, Amoedo ML, Borrás $M$, Pais $B$, Montoliu J. Tumoral calcinosis in haemodialysis patients without severe hyperparathyroidism. Nephrol Dial Transplant 8: 1270-1273, 1993.

14. Bover J, Ureña P, Brandenburg V, et al. Adynamic bone disease: from bone to vessels in chronic kidney disease. Semin Nephrol 34: 626-640, 2014.

15. Malluche HH. Aluminium and bone disease in chronic renal failure. Nephrol Dial Transplant 17 (Suppl 2): 21-24, 2002.

16. Marx SJ. Hyperparathyroid and hypoparathyroid disorders. N Engl J Med 343: 1863-1875, 2000.

17. Shanahan CM, Crouthamel MH, Kapustin A, Giachelli CM. Arterial calcification in chronic kidney disease: key roles for calcium and phosphate. Circ Res 109: 697-711, 2011.

18. Yamada S, Taniguchi $M$, Tokumoto $M$, Tsuruya $K$, Iida $M$. Osteoclast-like multi-nucleated giant cells in uraemic tumoral cal- cinosis. NDT Plus 2: 155-157, 2009.

19. Buonerba $C$, Caraglia M, Malgieri S, et al. Calcitriol: a better option than vitamin $\mathrm{D}$ in denosumab-treated patients with kidney failure? Expert Opin Biol Ther 13: 149-151, 2013.

20. Mitchell DM, Regan S, Cooley MR, et al. Long-term follow-up of patients with hypoparathyroidism. J Clin Endocrinol Metab 97: 4507-4514, 2012.

21. Helas S, Goettsch C, Schoppet M, et al. Inhibition of receptor activator of NF-kappaB ligand by denosumab attenuates vascular calcium deposition in mice. Am J Pathol 175: 473-478, 2009.

22. Samelson EJ, Miller PD, Christiansen C, et al. RANKL inhibition with denosumab does not influence 3-year progression of aortic calcification or incidence of adverse cardiovascular events in postmenopausal women with osteoporosis and high cardiovascular risk. J Bone Miner Res 29: 450-457, 2014.

23. Jaffer FA, Kim DE, Quinti L, et al. Optical visualization of cathepsin $\mathrm{K}$ activity in atherosclerosis with a novel, proteaseactivatable fluorescence sensor. Circulation 115: 2292-2298, 2007.

(C) 2015 The Japanese Society of Internal Medicine http://www.naika.or.jp/imonline/index.html 